\title{
Signet-ring cell adenoma of the thyroid and rheumatoid arthritis: incidental association or methotrexate-related change?
}

\author{
Adriana Handra-Luca \\ APHP Universite Paris Nord, France
}

Signet-ring cell change in thyroid adenoma is rarely reported [1-3]. We have recently seen such a tumour in a case of rheumatoid arthritis (RA) treated by methotrexate. Thyroid tumours are rarely reported in RA patients to our knowledge, mainly of carcinoma-type $[4,5]$. The thyroid resection was performed for recent increase in size of a left thyroid nodule. At macroscopy, the nodule measured $1.5 \times 2 \mathrm{~cm}$. On microscopy, the nodule showed follicular hyperplasia of adenoma type (the entire specimen was analysed on microscopy). A thin fibrous capsule could be focally seen as well as intranodular fibrosis foci. The thyrocytes were disposed in vesicles or solid buds. They showed nuclear atypias. Several foci of signet-ring thyrocytes were located both close to and far from the intranodular fibrotic zones (Fig. 1).

The intracytoplasmic vacuoles were faintly stained with Alcian-blue, and PAS and were negative for the proteins detected by immunohistochemistry. TTF1 was diffusely expressed in the nuclei of adenoma thyrocytes. HBME1 was negative while CK19 and CD138/syndecan-1 were focally expressed, CD138 including in the signet-ring thyrocytes. CK7 was diffusely expressed while CK20 and CD25 were negative. CD56/NCAM was diffusely expressed in the adenoma thyrocytes, mainly with a membrane pattern including in the signet-ring thyrocytes. CD68, negative in the thyrocytes (vacuolated or not) was positive in rare xanthomatous foci (intranodular or extranodular, in thyroiditis-type lesions). The non-nodular thyroid showed multifocal lymphocytic thyroiditis foci, perivascular and/or perivesicular, with several intravesicular multinucleated giant cells. CD25 was expressed in sparse lymphocytes (isolated or in the lymphocytic foci). S100 (negative in the thyroid adenoma) was positive in intrathyroid perivascular neural fibres and in nerves. A solid-cystic, multifocal solid-cell-nest (SCN) was also observed, peculiar by the CD138 expression.

The main differential diagnosis was that of intra-adenoma metastasis of a signet-ring cell-type carcinoma, gastric or extragastric. The diffuse expression of TTF1, thyroglobulin and thyroperoxidase along with the lack of CK2O allowed us to rule out this hypothesis. Of note would be the expression of CD138 in the thyroid adenoma including in the signet-ring thyrocytes as well as the expression of CD56. The precise involvement of these proteins in cytoplasmic changes leading to vacuole formation is difficult to precise, classical thyrocyte markers such as thyroglobulin, thyroperoxidase as well as cytokeratin CK7 being also expressed in the peri-vacuolar cytoplasm. However, the faint staining with Alcian-blue of the vacuole in the signet-ring thyrocytes remains incompletely elucidated: whether related to colloid change or of genuine mucoid nature [3]. The eventual impact of the autoimmune RA-related environment and/or the methotrexate treatment on changes in colloid cytoplasmic trafficking resulting in vacuole formation or on colloid composition is hypothetical and should be further studied.

Precising the nature of the multifocal accumulations of lymphocytes, perivascular, perivesicular and peri-SCN, and of the intraluminal multinucleated cells we have observed might be of clinical interest, whether related to the RAautoimmunity or to the methotrexate treatment, lymphoma regression being reported at methotrexate withdrawal in RA [6]. CD138-positive plasmocytes were almost absent in the thyroid lymphocytic foci, in contrast to the report of CD138-positive cells in synovia in RA [7]. Of note is the presence of rare CD25-positive lymphocytes, experimental data from animal models suggesting clinical potential for daclizumab in collagen-induced arthritis in rhesus monkeys [8].

In conclusion, we report a case of signet-ring cell thyroid adenoma occurring in rheumatoid arthritis treated by methotrexate. The histogenesis of the cytoplasmic vacuoles, negative for thyrocyte classical markes as well as for CD56 and CD138, remains to be elucidated.

The author declares no conflict of interest. 

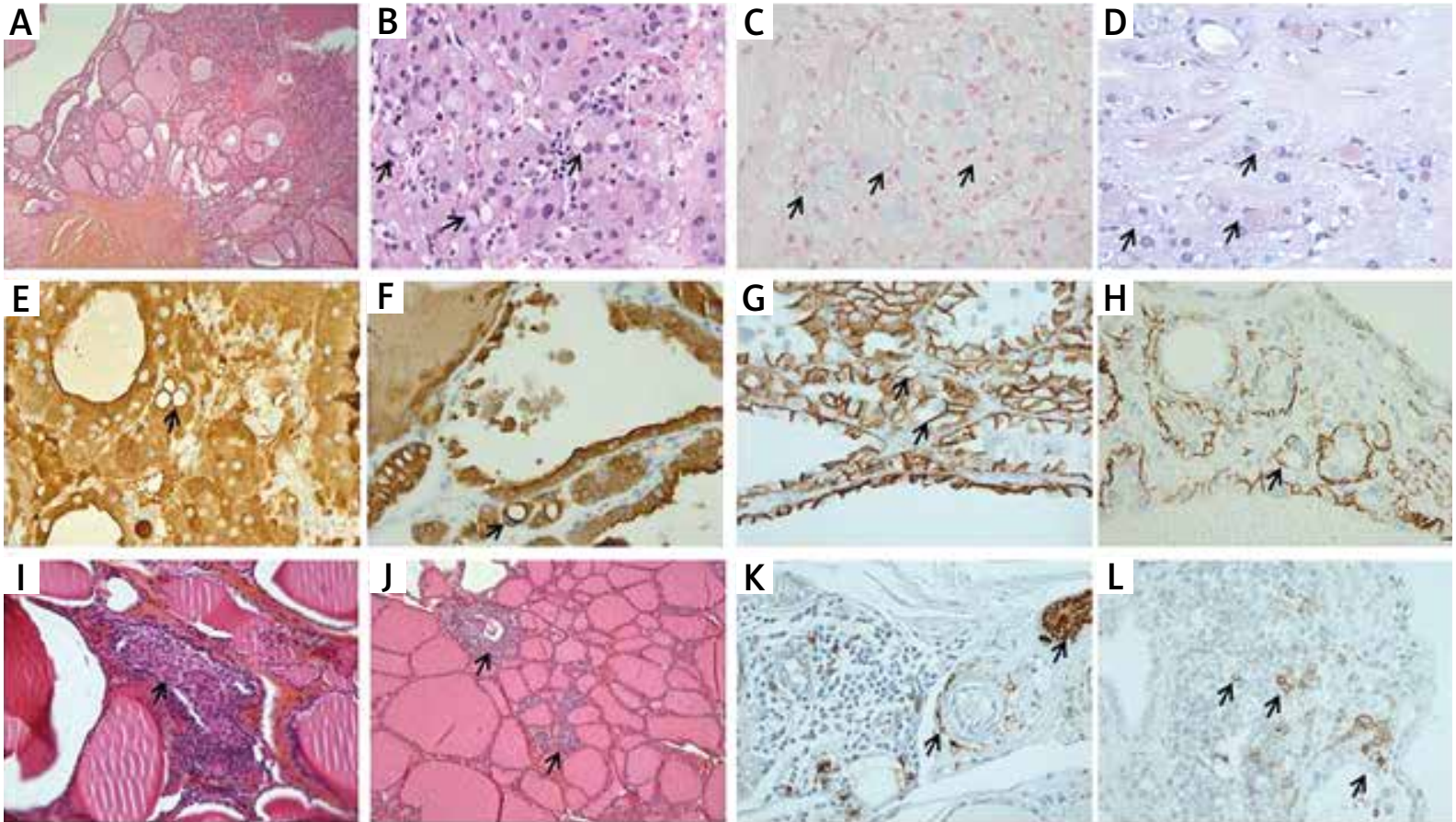

Fig. 1. The thyroid adenoma contained foci of fibrosis and numerous signet-ring thyrocytes (A). The intracytoplasmic vacuole of some signet ring thyrocytes was pale-pink on hematoxylin and eosin stain, pale blue on the Alcian blue stain and pink on the PAS stain (B, C, D, respectively: arrows for signet ring thyrocytes). The vacuole was optically blank on the thyroglobulin, thyroperoxidase, CD56 and CD138 immunohistochemistries ( $E, F, G$ and $H$, respectively: arrows for signet ring thyrocytes). Lymphocytic foci, perivascular, perivesicular (perineural) were seen in the non-nodular thyroid (I-L). Multinucleated giant cells were present in the vesicle lumina (I: arrow). Lymphocytic foci were also observed around the solid-cell-nests (J: arrows). To note are the perivascular lymphocytic foci at proximity of S100-positive vessels and intrathyroid nerves (K: arrows). CD25-positive lymphocytes (with focal exocytosis) were present in perivesicular lymphocytic foci (L: arrows). Original magnification $\times 5(\mathrm{~A}), \times 10(\mathrm{~J}), \times 20(\mathrm{I}), \times 40(\mathrm{~B}, \mathrm{C}, \mathrm{D}, \mathrm{E}, \mathrm{F}, \mathrm{G}, \mathrm{H}, \mathrm{K}, \mathrm{L})$.

\section{References}

1. Carcangiu ML, Sibley RK, Rosai J. Clear cell change in primary thyroid tumors. A study of 38 cases. Am J SurgPathol 1985; 9 : 705-722.

2. DeLellis RA, Lloyd RV, Heitz PU, Eng C. WHO/IARC Classification of Tumours Pathology and Genetics of Tumours of Endocrine Organs. $3^{\text {rd }}$ ed. Volume 8. IARC Press, Lyon 2004.

3. Rosai J. Rosai and Ackerman's Surgical Pathology.10th Edition Expert Consult. Elsevier Mosby, Philadelphia 2011.

4. Bakheet SM, Powe J. Fluorine-18-fluorodeoxyglucose uptake in rheumatoid arthritis-associated lung disease in a patient with thyroid cancer. J Nucl Med 1998; 39: 234-236.

5. Otsuka N, Fukunaga M, Morita K, et al. lodine-131 uptake in a patient with thyroid cancer and rheumatoid arthritis during acupuncture treatment. Clin Nucl Med 1990; 15: 29-31.

6. de Mast Q, Haverman J, Netten PM, Sinnige HA. Remission of a primary thyroid lymphoma after methotrexate withdrawal. Clin Endocrinol (Oxf) 2006; 64: 716-717.
7. Patterson AM, Cartwright A, David G, et al. Differential expression of syndecans and glypicans in chronically inflamed synovium. Ann Rheum Dis 2008; 67: 592-601.

8. Brok HP, Tekoppele JM, Hakimi J, et al. Prophylactic and therapeutic effects of a humanized monoclonal antibody against the IL-2 receptor (DACLIZUMAB) on collagen-induced arthritis (CIA) in rhesus monkeys.Clin Exp Immunol 2001; 124: 134-141. 